\title{
Different Degradation Patterns of Chiral Contaminant Enantiomers: Paclobutrazol as a Case Study
}

\author{
Hao-Ming Guo, ${ }^{a}$ Yue Zhao, ${ }^{a}$ Mei-Nan Ouyang ${ }^{a}$ and Zhong-Hua Yang ${ }^{\circledR *, a}$ \\ ${ }^{a}$ College of Plant Science and Technology, Department of Plant Protection, \\ Huazhong Agriculture University, 430070 Wuhan, China
}

\begin{abstract}
Studies often neglect the different trends between enantiomers in soil chiral contaminants. In the present study, paclobutrazol was chosen as the target analyte and the selective degradation patterns of this chiral pesticide were investigated in soils. After 14 days of culture, the degradation kinetics results demonstrated the degradation process of the two enantiomers conforms to first-order degradation kinetics equation, and the degradation rates were significantly different (paired $t$-test, $P<0.05)$. The degradation rate of $(2 S, 3 S)$-paclobutrazol $(S$-paclobutrazol) was higher than that of $(2 R, 3 R)$-paclobutrazol ( $R$-paclobutrazol), with the concentration decrease of 42.6 and $28.7 \%$, respectively. Meanwhile, the enantiomer fraction (EF) was 0.43 at final sampling point, and the half-life $\left(\mathrm{t}_{1 / 2}\right)$ of $S$-paclobutrazol and $R$-paclobutrazol were 17.3 and 28.9 days, which demonstrated significant enantioselective degradation. Results from this study served to enhance our understanding about the enantioselective degradation behaviors of chiral pesticides, which provided some scientific basis for the potential risk assessment of chiral pesticides in the environment.
\end{abstract}

Keywords: enantioselectivity, chiral pesticide, stereoselective degradation, environmental pollution, risk assessment

\section{Introduction}

For decades, people have paid close attention to soil contaminants to predict potential environmental problems caused by harmful substances. ${ }^{1,2}$ In contrast, the enantioselective degradation patterns between enantiomers in chiral contaminants are often overlooked and Utembe ${ }^{3}$ have reported the importance of studies about toxicity caused by chiral contaminants, but a fraction of studies investigated the different fate when chiral compounds enter the environment, which results in an absence of information regarding their enantioselectivity. The following are noteworthy problems in environmental assessment: $(i)$ achiral analyses provide only partial information which leads to inaccurate evaluation of chiral contaminant; (ii) enantiomeric effects on non-organism exist, so exploring the enantioselective degradation is necessary; and (iii) modeling risk remains imperfect and therefore challenging. Consequently, studying the enantioselective degradation of chiral pollutants in experiments that simulate environmental behaviors could provide a more accurate assessment of enantiomeric toxicity when chiral compounds enter in the environment.

*e-mail: yangzhonghua@mail.hzau.edu.cn
In this study, we focused on the degradation behaviors of chiral contaminants; and paclobutrazol was chosen as the model organic molecule. Paclobutrazol [(2RS,3RS)-1 - (4-chlorophenyl)-4,4-dimethyl2-(1H-1,2,4-trizol-1-yl)pentan-3-ol] is one of the most commonly used plant growth regulator in the world. However, some researchers indicated that pesticides can spread throughout ecosystems by leaching and runoff from soil into ground and surface water. ${ }^{2,4}$ The high solubility of paclobutrazol have resulted in serious environmental problems and poses extreme threats to human and ecosystem health. To our knowledge, the commercial paclobutrazol forms consist of one pair of enantiomers $(2 S, 3 S ; 2 R, 3 R) .{ }^{5}$ Meanwhile, these two enantiomers have different activities, $R$-paclobutrazol has proved to be good fungicidal, and $S$-paclobutrazol could play an important role in regulating plant growth. ${ }^{6}$ In addition, the chiral structure also can lead to selective degradation and enantiomeric toxicities for non-target organisms when paclobutrazol is released into the surrounding environment. ${ }^{7-9}$

The stereoselectivity of chiral pesticides in the environment has been widely reported. Isocarbophos was studied and the results showed $S$-isocarbophos was more persistent than $R$-form in some matrices of rice field 
and the enantiomers displayed different bioactivities and toxicities. ${ }^{10}$ Some chiral pesticides had been demonstrated that enantiomeric bioactivities and enantioselective environmental behaviors were observed once they enter the ecosystem. ${ }^{11-13}$ The difference of biological activity between enantiomers of chiral pesticides caused their different degradation rates in different environmental matrices, ${ }^{14,15}$ those that were not degraded might pose greater environmental risks. Once these compounds enter an organism as enantiomers, they will react selectively to chiral receptors in the body, causing adverse effects such as enzyme activity, gene transcription and endocrine disrupting, ${ }^{3,14,16}$ and other enantioselective effects have also been reported ${ }^{17-19}$ in biological metabolic and environmental microbial diversity. Therefore, it is essential and urgent to investigate the environmental behaviors of chiral pesticides from enantiomers level.

Paclobutrazol is a primary contaminant in agricultural lands, however, only a few studies have reported degradation variation between paclobutrazol enantiomers. Our former study ${ }^{18}$ compared the different degradation behaviors of paclobutrazol during Chinese cabbage pickling process and exhibited a significant selective degradation process between these two enantiomers. Paclobutrazol contains two stereogenic centers and consists of two pairs of enantiomers in theory. However, the commercial paclobutrazol only consists of $(2 S, 3 S)$ paclobutrazol and $(2 R, 3 R)$-paclobutrazol due to their much higher fungicidal and plant-growth regulatory activities than the other two. Recently, another study ${ }^{19}$ investigated the different toxicity of paclobutrazol to the Chlorella vulgaris, and results showed that $R$-enantiomer was found to be more toxic to Chlorella vulgaris cells than $S$-enantiomer and racemate.

The current study was designed to investigate different enantiomer degradation patterns. The environmental soil sample was collected in Huazhong Agricultural University and was taken to explore the stereoselective behaviors of the chiral pesticide paclobutrazol. Results from this study may improve a basis for predicting potential risks to the environment and human health after the application of chiral paclobutrazol.

\section{Experimental}

\section{Chemicals and reagents}

Paclobutrazol (Figure 1) racemic standard was purchased from Green Herbs Co. Ltd. (Beijing, China) with a purity of $95 \%$. HPLC (high performance liquid chromatography)-grade methanol was obtained from Fisher
Scientific (Waltham, Massachusetts, USA). The stock standard solution prepared from methanol and standard working solution was diluted from stock solution. The stock standard solution and standard working solution were stored at $4{ }^{\circ} \mathrm{C}$ in the dark for later use. Methanol, ethyl acetate, anhydrous sodium sulfate, sodium chloride and all other agents of analytical grade were provided by Sinopharm Chemical Reagent Co. Ltd. (Shanghai, China). The ultrapure water was made by Milli-Q system (Bedford, MA, USA).

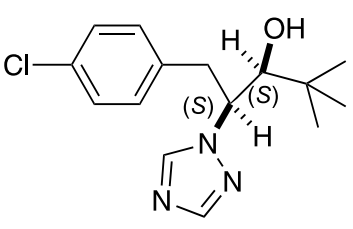

$(2 S, 3 S)-(-)-$ Paclobutrazol

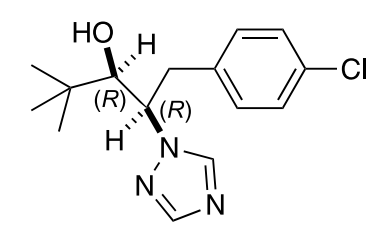

$(2 R, 3 R)-(+)-$ Paclobutrazol
Figure 1. Chemical structure of paclobutrazol enantiomers.

\section{Soil collection}

The soil samples were collected from Huazhong Agricultural University in Wuhan, China. Following removal of the superficial vegetation, topsoil $(0-10 \mathrm{~cm})$ was collected. The soils were sieved ( $2 \mathrm{~mm}$ screen size), air-dried at room temperature, maintained in the dark, and tested within a few days. Blank soil determinations were performed, and target analytes were not detected.

Incubation in soil

Different degradation patterns among enantiomers were investigated by incubating the following unsterilized soils separately: (i) racemic (containing both enantiomers); and (ii) blank control (without both enantiomers). In this study, all soil samples were incubated using $1000 \mathrm{~mL}$ beakers covered with sterile gauze and cotton plugs. Sterile gauze and cotton plugs could maintain the initial moisture level and the concentration of oxygen during the incubation period, meanwhile, it also could reduce the effect of evaporation on the racemic pesticides and their degradation metabolites. For the incubated experiment, a $3 \mathrm{~mL}$ portion of standard solution $\left(1 \mathrm{mg} \mathrm{mL}^{-1}\right.$, target analyte concentration in methanol) was added to $200 \mathrm{~g}$ of air-dry soil first to ensure the $200 \mathrm{~g}$ of soil was homogeneously spiked. After stirring for $10 \mathrm{~min}$, which allowed the methanol to evaporate and the target analytes to be evenly distributed, another $400 \mathrm{~g}$ of soil was added and mixed thoroughly, yielding a final $5 \mathrm{mg} \mathrm{kg}^{-1}$ fortification level of racemic. The spiked soil sample was incubated at $25^{\circ} \mathrm{C}$ under dark condition. During the incubation, $10 \mathrm{~g}$ soil 
was removed at different time and transferred to a freezer $\left(-20^{\circ} \mathrm{C}\right)$ to stop the incubation process.

\section{Extraction method}

The soil samples were first thawed at room temperature, and paclobutrazol was extracted from the soil sample by $20 \mathrm{~mL}$ acetonitrile placed in a $50-\mathrm{mL}$ polypropylene centrifuge tube containing $10 \mathrm{~g}$ of incubated soil. The tube was capped immediately; the soil mixture was then stirred for $5 \mathrm{~min}$ on a vortex mixer and sonicated for $10 \mathrm{~min}$ in an ultrasonic bath to extract the target analytes. After extraction, the mixture was centrifuged at $5000 \mathrm{rpm}$ for $5 \mathrm{~min}$. The extraction and centrifuge steps were repeated twice. The solvents were combined and passed through a funnel with approximately $5 \mathrm{~g}$ of anhydrous sodium sulfate and collected in a pear-shaped flask, then evaporated to dryness under $40 \mathrm{rpm}$ with a vacuum rotary evaporator at $35^{\circ} \mathrm{C}$. The dry extract was diluted with $1 \mathrm{~mL}$ methanol and filtered through a $0.22 \mu \mathrm{m}$ filter membrane to form final sample solution.

HPLC analysis

Paclobutrazol enantiomers were separated and determined on Agilent 1200 HPLC (Agilent 1260 equipped with the G1311A pump, G1322A degasser, G1329A ALS, and G1314B VWD). The injection volume was $20 \mu \mathrm{L}$, and UV detection wavelength was $230 \mathrm{~nm}$. The signal was received and processed by using Agilent ChemStation software. The mobile phase was a mixture of methanol and water $(80 / 20, \mathrm{v} / \mathrm{v})$ with a flow rate of $0.7 \mathrm{~mL} \mathrm{~min}^{-1}$ at $30{ }^{\circ} \mathrm{C}$. The chiral column was CDMPC-CSP (cellulosetri[3,5-dimethyl-phenylcarbamate]-based chiral stationary phase, W250 $\times 4.6 \mathrm{~mm}$ internal diameter $(5 \mu \mathrm{m}))$ purchased from Welch Materials, Inc. (Shanghai, China) and the column temperature was controlled by an AT-930 heater and cooler column attemperator (Tianjin Automatic Science Instrument Co. Ltd., China).

\section{Data analysis}

The resolution $\left(\mathrm{R}_{\mathrm{S}}\right)$ was calculated from the formula:

$$
\mathrm{R}_{\mathrm{S}}=\frac{2\left(\mathrm{t}_{2}-\mathrm{t}_{1}\right)}{\left(\mathrm{w}_{1}+\mathrm{w}_{2}\right)}
$$

where $t_{1}$ and $t_{2}$ are retention times for the two eluted enantiomers, and $\mathrm{w}_{1}$ and $\mathrm{w}_{2}$ are the chromatographic peak widths.

The degradation rate constant $(\mathrm{k})$ and half-life $\left(\mathrm{t}_{1 / 2}\right)$ were obtained from the first-order kinetics equations:
$\mathrm{C}=\mathrm{C}_{0} \mathrm{e}^{-\mathrm{kt}}$

$\mathrm{t}_{1 / 2}=\frac{\ln 2}{\mathrm{k}}=\frac{0.693}{\mathrm{k}}$

where $\mathrm{C}_{0}\left(\mathrm{mg} \mathrm{kg}^{-1}\right)$ and $\mathrm{C}\left(\mathrm{mg} \mathrm{kg}^{-1}\right)$ are the concentrations of the enantiomer at times 0 and $t$, respectively.

The enantiomer fraction (EF) was used to assess the enantioselectivity of chiral pesticides. It was defined as follows:

$\mathrm{EF}=\frac{[S]}{[S]+[R]}$

where $[S]$ and $[R]$ are the peak areas of $S$-enantiomer and $R$-enantiomer, respectively. The $\mathrm{EF}$ values range from 0 to 1 , and $\mathrm{EF}=0.5$ means the racemic.

\section{Results and Discussion}

\section{Calibration and method validation}

Under the HPLC condition, the standard solution of racemic paclobutrazol could be separated into $R$-paclobutrazol and $S$-paclobutrazol completely with an $\mathrm{R}_{\mathrm{S}}$ of 2.84 , and there was no interference peak as shown in Figure 2. The elution orders of the two enantiomers were confirmed by comparing their retention times. According to the previous studies, ${ }^{20-22}$ the $S$-paclobutrazol was first eluted at $8 \mathrm{~min}$ and $R$-paclobutrazol at $11 \mathrm{~min}$.

A series of standard solutions $\left(0.5,1,10,50 \mathrm{mg} \mathrm{L}^{-1}\right.$ for each enantiomer) prepared from a stock standard solution were detected. Excellent linear relationships were obtained for the two enantiomers within the range of $0.5-50 \mathrm{mg} \mathrm{L}^{-1}$ and the linear equations were $y=34.459 x+5.1762$ (coefficient of determination $\left(\mathrm{R}^{2}\right)=0.9995$ ) for $S$-paclobutrazol and $y=34.376 x+8.3808\left(\mathrm{R}^{2}=0.9992\right)$ for $R$-paclobutrazol, ensuring that the two enantiomers in the sample could be accurately calculated.

The addition and recovery experiments demonstrated the extraction method described was available for this study as shown in Table 1. The recoveries were obtained in the range of $71.3-86.7 \%$ and $85.8-107.3 \%$ for $S$-enantiomer and $R$-enantiomer, respectively. For both enantiomers, the RSD ranged from 3.0-8.6\%. The above content showed that the extraction method was effective and reliable for this research.

Degradation of paclobutrazol isomers in the cultivated soil

The degradation kinetics curves were shown in Figure 3 and the relative data were listed in Table 2. After 14 days 


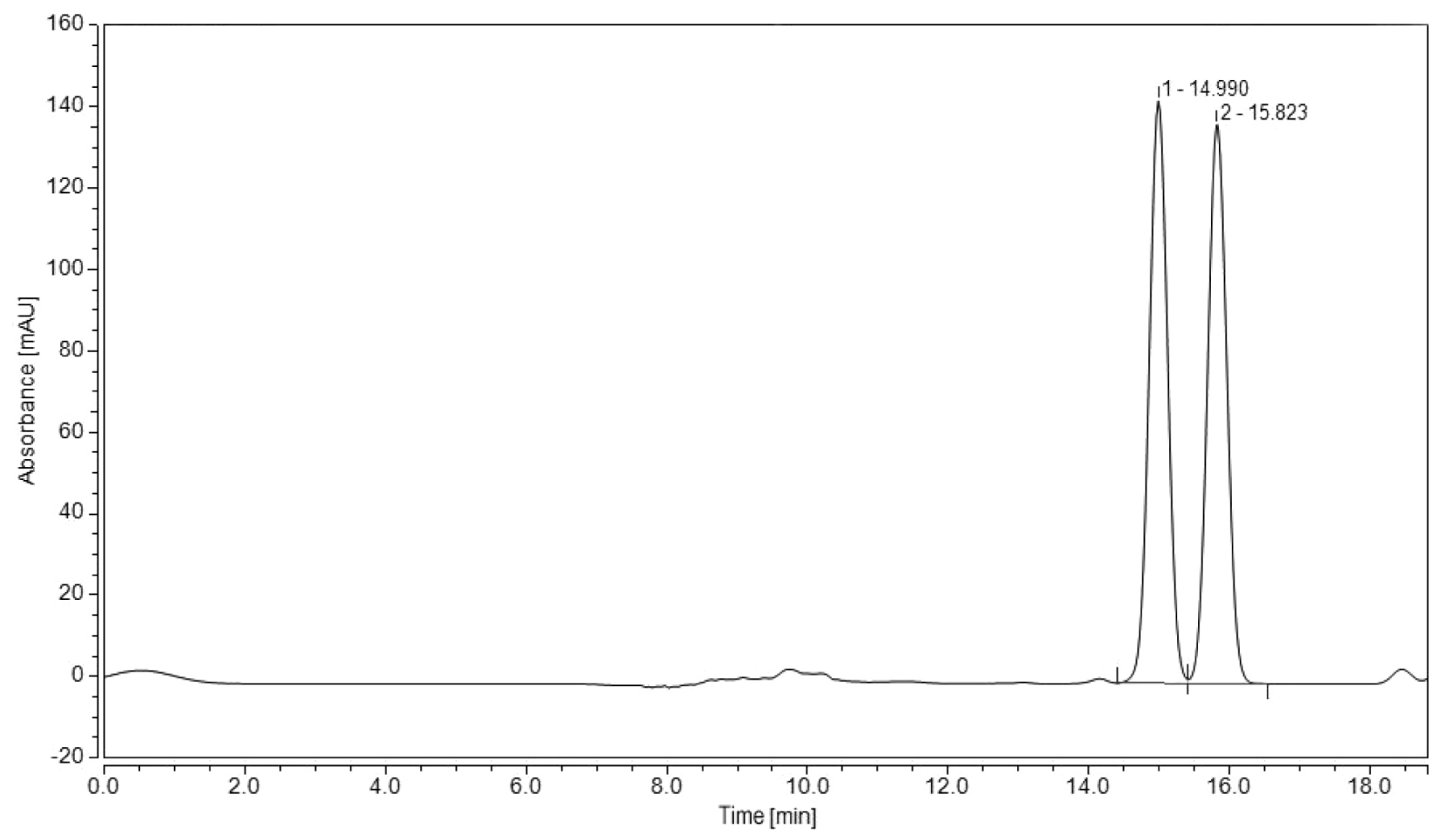

Figure 2. High performance liquid chromatography spectrum of chiral pesticide paclobutrazol ( $S$-enantiomer and $R$-enantiomer).

Table 1. Recoveries and RSD for paclobutrazol enantiomers in fortified samples

\begin{tabular}{|c|c|c|c|c|c|c|c|c|}
\hline \multirow{2}{*}{ Sample } & \multirow{2}{*}{ Chemical } & \multirow{2}{*}{$\begin{array}{c}\text { Level/ } \\
\left(\mathrm{mg} \mathrm{kg}^{-1}\right)\end{array}$} & \multicolumn{3}{|c|}{ Recovery / \% } & \multirow{2}{*}{ Average / \% } & \multirow{2}{*}{$\mathrm{SD} / \%$} & \multirow{2}{*}{$\mathrm{RSD} / \%$} \\
\hline & & & $\mathrm{n}=1$ & $\mathrm{n}=2$ & $\mathrm{n}=3$ & & & \\
\hline \multirow{4}{*}{ Soil } & $R$-PBZ & \multirow{2}{*}{1} & 90.2 & 94.8 & 107.3 & 97.5 & 7.2 & 7.4 \\
\hline & $S$-PBZ & & 71.3 & 74.2 & 86.7 & 77.4 & 6.7 & 8.6 \\
\hline & $R$-PBZ & \multirow{2}{*}{5} & 93.0 & 86.7 & 85.8 & 88.5 & 3.2 & 3.6 \\
\hline & $S$-PBZ & & 84.3 & 79.4 & 78.9 & 80.89 & 2.4 & 3.0 \\
\hline
\end{tabular}

SD: standard deviation; RSD: relative standard deviation; $R$-PBZ: $(2 R, 3 R)$-paclobutrazol; $S$-PBZ: $(2 S, 3 S)$-paclobutrazol.

of incubation, we assumed paclobutrazol degradation followed first order kinetics. Regression analyses exhibited good fit of the data, with $\mathrm{R}^{2}$-values ranging from 0.8883 to 0.9547 . The degradation kinetics results demonstrated the two enantiomers degradation rates were significantly different (paired $t$-test, $P<0.05$ ). In addition, results showed $S$-paclobutrazol degraded faster in soils. The $\mathrm{t}_{1 / 2}$ of $S$-enantiomer and $R$-enantiomer were 17.3 and 28.9 days, respectively $(P<0.05)$. Notably, the concentrations of $S$-paclobutrazol and $R$-paclobutrazol were obviously different and decreased by 42.6 and $28.7 \%$, respectively. Jia et $a l{ }^{21}$ demonstrated the enantiomers of glufosinate displayed different degradation rate in soil and water, which may cause one of the enantiomers enrich in the environment. According to previous studies, ${ }^{22,23}$ enantioselective degradation of triadimefon was found in soil, in addition, the stereoselective enrichment of triadimefon was observed by Scenedesmus obliquus, which resulted in stereoselective toxicity. Liu et al. ${ }^{19}$ reported enantioselective growth inhibition of the green algae induced by two paclobutrazol enantiomers, and the toxicity caused by $R$-paclobutrazol was stronger than $S$-paclobutrazol. In the present study,

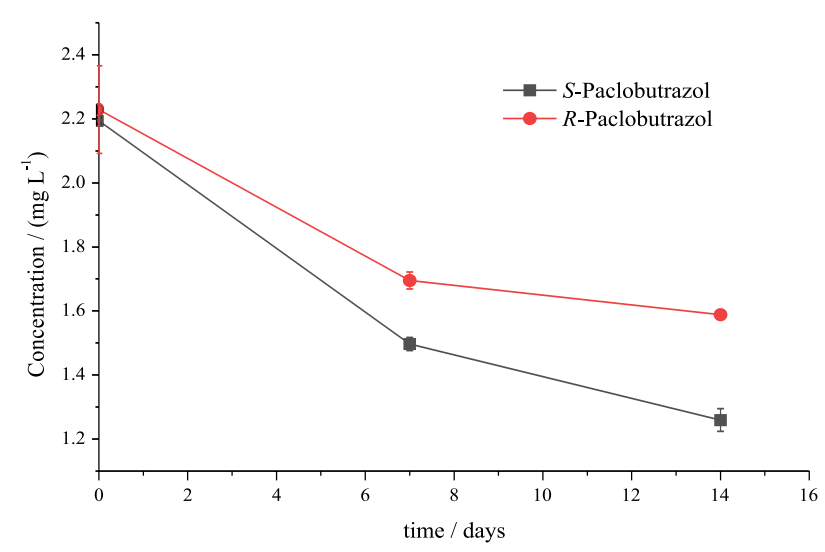

Figure 3. Degradation kinetics curves of paclobutrazol enantiomers in the spiked soil during incubation. 
Table 2. First-order degradation kinetic equation, rate constant $(\mathrm{k})$, half-life $\left(\mathrm{t}_{1 / 2}\right)$ for the two enantiomers in the soil

\begin{tabular}{|c|c|c|c|c|c|}
\hline Incubated compound & $\begin{array}{c}\text { Degradation kinetic } \\
\text { equation }\end{array}$ & $\mathrm{k} /$ day $^{-1}$ & $\mathrm{R}^{2}$ & $\mathrm{t}_{1 / 2} /$ days & $P^{\text {a }}$ \\
\hline$S$-Paclobutrazol & $y=2.119 \mathrm{e}^{-0.040 x}$ & 0.04 & 0.9547 & 17.325 & 0.019 \\
\hline$R$-Paclobutrazol & $y=2.1531 \mathrm{e}^{-0.024 x}$ & 0.024 & 0.8883 & 28.875 & \\
\hline
\end{tabular}

a $P<0.05$ indicates that the half-lives of $S$-paclobutrazol and $R$-paclobutrazol are significantly different. $\mathrm{R}^{2}$ : coefficient of determination; $S$-Paclobutrazol: $(2 S, 3 S)$-paclobutrazol; $R$-Paclobutrazol: $(2 R, 3 R)$-paclobutrazol.

$R$-paclobutrazol showed a more permanent presence in the soil, which could lead to enantiomeric toxicity for nontarget organisms that live in soil and plants that grow above it. Chen et al. ${ }^{24}$ explored enantioselective phytotoxic disturbances of fatty acids in Arabidopsis thaliana by dichlorprop, therefore, $R$-paclobutrazol residue in the soil may cause the negative effects on non-organism around the soil.

Yang and $\mathrm{Ji}^{25}$ reported functional genes during the degradation of beta-cypermethrin in soil, and the results demonstrated that functional genes were enantioselective to enantiomers. We speculated that the reason for enantioselective degradation may be that the two enantiomers have different biological activities which lead to different degradation rates under the action of the enzyme in the soil. Therefore, further study of the mechanism of pesticide degradation is needed.

\section{Change of EF value during culture}

In this case, we calculated the EF to evaluate the selective degradation behaviors of paclobutrazol and the change of EF values was displayed in Figure 4. The racpaclobutrazol EF values decreased continuously during the degradation process, which demonstrated $S$-enantiomers degraded faster than its antipode significantly $(P<0.05)$, and enantiomerization and racemization were not observed. $R$-Paclobutrazol could provide fungicidal

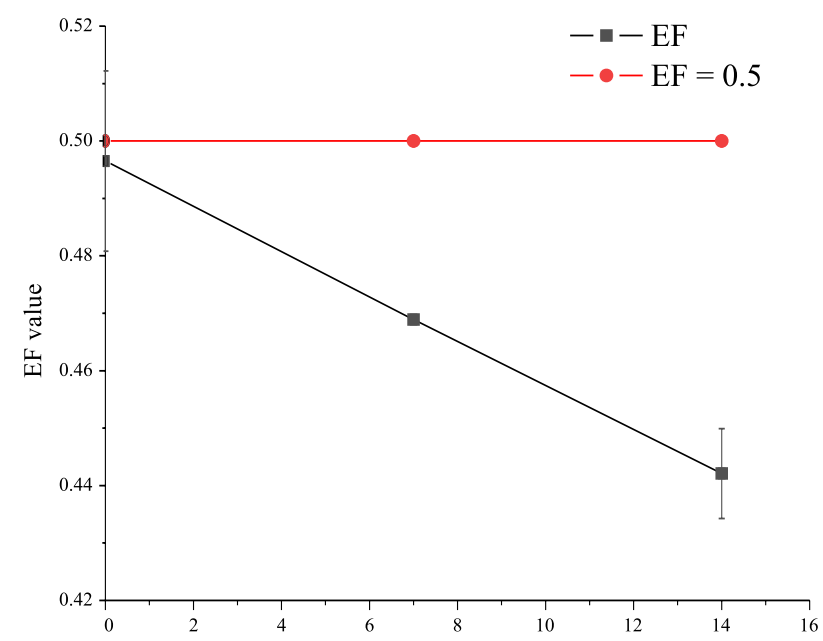

Figure 4. Change of EF value of paclobutrazol. activity which could pose a potential risk to environmental microbes and other non-organisms. Wang et al. ${ }^{26}$ reported that $R$-paclobutrazol could enrich in peach; the same phenomenon was found in rat livers. ${ }^{27}$ Results above supported markedly selective degradation behaviors during rac-paclobutrazol degradation in tested soils.

\section{Conclusions}

The enantiomers of chiral pesticides usually show different bioactivities which cause different degradation behavior and toxicities in the environment. Only by studying the environmental pollution of chiral pesticides at the level of enantiomer morphology is possible to understand their behaviors and effects in the environment exactly and evaluate their risks to human health and ecosystem accurately. This study demonstrated that the two enantiomers of paclobutrazol displayed stereoselectivity in the soil and $R$-paclobutrazol had more residual danger than $S$-paclobutrazol, nevertheless, the mechanism of enantioselective degradation of paclobutrazol was not identified, therefore, further study is necessary. The result could provide a basis for the assessment of the environmental pollution of paclobutrazol.

\section{Acknowledgments}

The present study was supported by grants from the National Key R\&D Program of China (2017YFD020030803) and National Natural Science Foundation of China (No. 21507032).

\section{References}

1. Jiang, R.; Wang, M.; Chen, W.; Li, X.; Balseiro-Romero, M.; Baveye, P. C.; Environ. Pollut. 2019, 255, 113184.

2. Lupi, L.; Bedmar, F.; Wunderlin, D. A.; Miglioranza, K. S. B.; Environ. Earth Sci. 2019, 78, 569.

3. Utembe, W.; Toxicol. Lett. 2019, 311, 58.

4. Dragon, K.; Drozdzynski, D.; Gorski, J.; Kruc, R.; Environ. Earth Sci. 2019, 78, 593.

5. Wu, C. W.; Sun, J. Q.; Zhang, A. P.; Liu, W. P.; Environ. Sci. Technol. 2013, 47, 843. 
6. Sugavanam, B.; Pestic. Sci. 2010, 15, 296.

7. Lenton, J.; Appleford, N.; Temple-Smith, K.; Plant Growth Regul. 1994, 15, 281.

8. Di, S. S.; Cang, T.; Qi, P. P.; Wang, X. Y.; Xu, M. F.; Wang, Z. W.; Xu, H.; Wang, Q.; Wang, X.-Q.; J. Hazard. Mater. 2019, 375, 305.

9. Buerge, I. J.; Kasteel, R.; Bächli, A.; Poiger, T.; Environ. Sci. Technol. 2019, 53, 5733.

10. Chen, S. Y.; Zhang, L. J.; Chen, H.; Chen, Z. W.; Wen, Y. Z.; J. Agric. Food Chem. 2019, 67, 1631.

11. Wang, S. H.; Li, H. Z.; You, J.; Sci. Total Environ. 2019, 672, 335.

12. Zhao, P. F.; Wang, Z. K.; Gao, X.; Guo, X. J.; Zhao, L. S.; Food Chem. 2019, 277, 298.

13. Buerge, I. J.; Bächli, A.; Kasteel, R.; Portmann, R.; LópezCabeza, R.; Schwab, L. F.; Poiger, T.; Environ. Sci. Technol. 2019, 53, 5725.

14. Ji, C. Y.; Yu, C.; Yue, S. Q.; Zhang, Q.; Yan, Y. L.; Fan, J.; Zhao, M. R.; Chemosphere 2019, 220, 766.

15. Qian, H. F.; Wang, R. Q.; Hu, H. J.; Lu, T.; Chen, X. L.; Ye, H. Q.; Liu, W. P.; Fu, Z. W.; Environ. Sci. Technol. 2011, 45, 7036.

16. Jia, M.; Wang, Y.; Wang, D. Z.; Teng, M. M.; Yan, J.; Yan, S.; Meng, Z. Y.; Li, R. S.; Zhou, Z. Q.; Zhu, W. T.; Chemosphere 2019, 226, 520.
17. Zakaria, D.; Lappin-Scott, H.; Burton, S.; Whitby, C.; Environ. Microbiol. 2007, 9, 2575.

18. Zhao, Y.; Ouyang, M. N.; Xiong, Y. B.; Wang, D. D.; Guo, H. M.; Yang, Z. H.; Chirality 2019, 31, 230.

19. Liu, C. X.; Liu, S. Z.; Diao, J. L.; Environ. Pollut. 2019, 250, 610.

20. Li, Y. B.; Dong, F. S.; Liu, X. G.; Xu, J.; Li, J.; Kong, Z. Q.; Chen, X.; Song, W. C.; Wang, Y. H.; Zheng, Y. Q.; J. Chromatogr. A 2012, 38, 51.

21. Jia, G.; Xu, J.; Long, X.; Ge, S.; Chen, L.; Hu, D.; Zhang, Y.; J. Agric. Food Chem. 2019, 67, 11312.

22. Xu, P.; Huang, L.; Chirality 2017, 29, 61.

23. Li, Z.; Li, Q.; Zhao, J.; Wang, W.; Chirality 2013, 25, 355.

24. Chen, S. Y.; Chen, H.; Chen, Z. W.; Wen, Y. Z.; Liu, W. P.; Environ. Sci. Technol. 2019, 53, 9252.

25. Yang, Z. H.; Ji, G. D.; J. Hazard. Mater. 2015, 299, 719.

26. Wang, X. Y.; Qi, P. P.; Yang, G. L.; Wang, X. Q.; Zhang, H.; Xu, H.; Wang, Z. W.; Wang, Q.; Chirality 2014, 26, 400.

27. Wu, S.; Yu, M.; Zhang, H.; Han, J. Z.; Qian, M. R.; Chirality 2015, 27, 344. 